\title{
Genetic variability of XRCC1 influences the treatment outcome of gastric cancer
}

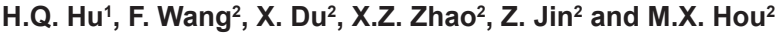 \\ 'Department of Digestive System, \\ the Affiliated Hospital of Inner Mongolia Medical University, Hohhot, China \\ 2Department of Gastrointestinal Surgery, \\ the Affiliated Hospital of Inner Mongolia Medical University, Hohhot, China \\ Corresponding author: M.X. Hou \\ E-mail: houmjj@163.com \\ Genet. Mol. Res. 15 (1): gmr.15017452 \\ Received August 14, 2015 \\ Accepted November 5, 2015 \\ Published February 5, 2016 \\ DOI http://dx.doi.org/10.4238/gmr.15017452
}

\begin{abstract}
We aimed to investigate the role of XRCC1 codon 194 (Arg>Trp), 280 (Arg>His), and 399 (Arg>Gln) polymorphisms in response to chemotherapy and the overall survival of gastric cancer patients. A total of 172 patients were recruited for our study between January 2010 and March 2012. Genotyping of the three XRCC1 codons was carried out by restriction fragment length polymorphism polymerase chain reaction. By logistic regression analysis, we found that the Trp/Trp genotype of XRCC1 194 (Arg>Trp) showed a stronger association with complete or partial response to chemotherapy compared to the Arg/Arg genotype, and the adjusted odds ratio $(95 \% \mathrm{Cl})$ was $0.17(0.05-0.58)$. Moreover, the Trp/Trp genotype was associated with a higher risk of death than that with the Arg/ Arg genotype based on multivariate Cox proportional hazard regression analysis, and the adjusted hazard ratio $(95 \% \mathrm{Cl})$ was $4.08(1.20-14.19)$. In conclusion, we found that the XRCC1 194 (Arg>Trp) polymorphism was correlated with a better response to chemotherapy and a low risk of death in patients with gastric cancer.
\end{abstract}

Key words: XRCC1; Polymorphism; Gastric cancer 


\section{INTRODUCTION}

Gastric cancer is the fifth most common malignancy in the world, after lung, breast, colorectum, and prostate cancer. It is estimated that, in 2012, there were one million new cases of gastric cancer worldwide. More than $70 \%$ of all the cases $(677,000$ cases) occur in developing countries (456,000 in men, 221,000 in women), and 50\% occur in Eastern Asia (mainly in China) (International Agency for Research on Cancer, 2012). Gastric cancer can be successfully treated if tumors are discovered at an early stage and surgically removed; however, most patients are diagnosed at an advanced stage. Currently, systemic chemotherapy is the primary treatment option for advanced gastric cancer, but the development of resistance is a major cause for the failure of chemotherapy over time. The TNM stage (classifying the size of the primary tumor, involvement of lymph nodes, and metastasis) and age of the patient both influence the prognosis, but the treatment outcome of gastric cancer is highly variable across individuals. Genetic factors may play a role in the prognosis of gastric cancer, and therefore, the identification of biomarkers is a research priority.

X-ray repair cross-complementing group 1 (XRCC1) is an important member of the base excision repair (BER) pathway, which plays a prominent role in both single-strand break repair (SSBR) and BER (Lindahl and Wood, 1999). XRCC1 functions in complex with many other components to repair DNA damage upon exposure to endogenous reactive oxygen species, ionizing radiation, or alkylating agents (Thompson and West, 2000; Duell et al., 2001). Previous experimental studies have reported that the BER pathway mainly removes non-bulky base adducts produced by methylation, ionizing radiation, or oxidative damage (Duarte et al., 2005). XRCC1 interacts with ligase and poly (ADP-ribose) polymerase to efficiently repair DNA damage, including platinum-based chemotherapy-induced damage (Xu et al., 2014). Three common SNPs have been identified in XRCC1, at codon 194 (Arg>Trp), 280 (Arg>His), and 399 (Arg>Gln). In this study, we investigate the role of these 3 SNPs in response to chemotherapy and the overall survival of gastric cancer patients.

\section{MATERIAL AND METHODS}

\section{Study subjects}

A total of 172 gastric cancer patients were recruited from the Affiliated Hospital of Inner Mongolia Medical University between January 2010 and March 2012. Patients with gastric cancer were independently diagnosed by two histopathologists. The stage of gastric cancer was classified according to the TNM stage system of the Union for International Cancer Control and the American Joint Committee on Cancer. Patients were excluded if they had previously received any targeted therapy, radiotherapy, chemotherapy, and/or intervention therapy for gastric cancer. Patients provided informed written consent prior to enrollment and the study was reviewed and approved by the Ethics Committee of the Affiliated Hospital of Inner Mongolia Medical University.

\section{Assessment of treatment outcome}

After recruitment, all the patients received platinum-based chemotherapy. 
Demographic, clinical, and treatment parameters were collected from the medical records, including information on gender, age, Lauren's type, TNM stage, tumor size, and metastasis. Response to chemotherapy was assessed according to the response evaluation criteria in solid tumors (RECIST) (Therasse et al., 2000). Complete response (CR) and partial response (PR) were combined as responders, and stable disease (SD) and progressive disease (PD) were grouped as non-responders. Overall survival (OS) was used to evaluate the treatment outcome of gastric cancer, and was calculated based on the date of assignment and either the date of death, due to any cause, or of the last clinical follow-up. Patients follow-up occurred every 4 weeks, either by telephone or at the clinic. The follow-up of the gastric cancer patients was completed in March 2015.

\section{DNA extraction and genotyping}

Before receiving chemotherapy, $4 \mathrm{~mL}$ peripheral blood was taken from each patient, and samples were stored at $-20^{\circ} \mathrm{C}$. The DNA was extracted from peripheral blood using the Qiagen blood mini kit (Qiagen, Germany). The polymerase chain reaction (PCR) primers for XRCC1 codons 194 (Arg>Trp), 280 (Arg>His), and 399 (Arg>Gln) were designed using the Sequenom Assay Design 3.1 software (Sequenom Inc., San Diego, CA, USA). Genotyping of XRCC1 codons 194 (Arg>Trp), 280 (Arg>His), and 399 (Arg>Gln) was carried out by restriction fragment length polymorphism-PCR. The PCR was carried out as follows: $95^{\circ} \mathrm{C}$ for 5 min for the initial denaturation, followed by 30 cycles of denaturation at $95^{\circ} \mathrm{C}$ for $30 \mathrm{~s}$, annealing at $62^{\circ} \mathrm{C}$ for $45 \mathrm{~s}$, and extension at $72^{\circ} \mathrm{C}$ for $30 \mathrm{~s}$, and a final extension at $72^{\circ} \mathrm{C}$ for $5 \mathrm{~min}$. Additionally, approximately $10 \%$ of the samples were randomly selected and retested, and the results were $100 \%$ concordant.

\section{Statistical analysis}

Frequencies were used to describe the distribution of categorical variables, while median values and interquartile ranges were used for continuous variables. The role of genetic polymorphisms in the response to chemotherapy was assessed by logistic regression analysis and the results were determined by odds ratios (ORs) and their 95\% confidence interval $(\mathrm{Cl})$. Multivariate Cox proportional hazard regression analysis was performed to analyze the association between genetic polymorphisms in XRCC1 and OS of gastric cancer patients after adjustment for confounding factors. OS was estimated using the Kaplan-Meier method, and all point estimates were accompanied by $95 \% \mathrm{Cls}$. All tests were two-sided and $\mathrm{P}<0.05$ was considered statistically significant. Statistical analysis was conducted using the SPSS 16.0 software package (SPSS Inc., Chicago, IL, USA).

\section{RESULTS}

The median age of the patients with gastric cancer included in this study was $69.30 \pm 11.57$ years. Of the 172 patients, $58(33.72 \%)$ were females and $114(66.28 \%)$ were males. Clinically, $73(42.44 \%)$ cases were of the intestinal type, $99(57.56 \%)$ were diffuse. Ninety-eight $(56.98 \%)$ patients were at TNM stage III-IV, $90(52.33 \%)$ had a tumor size $\geq 5 \mathrm{~cm}$, and $110(63.95 \%)$ showed metastasis (Table 1). 


Table 1. Characteristics of gastric cancer patients.
\begin{tabular}{l|c|c}
\hline Variables & Number & $\%$ \\
\hline Mean age (years) & $69.30 \pm 11.57$ & 41.86 \\
\hline$<65$ & 72 & 58.14 \\
\hline$\geq 65$ & 100 & 33.72 \\
\hline Gender & & 66.28 \\
\hline Female & 58 & 42.44 \\
\hline Male & 114 & 57.56 \\
\hline Lauren's type & & \\
\hline Intestinal & 73 & 43.02 \\
\hline Diffuse & 99 & 56.98 \\
\hline TNM stage & & \\
\hline I-II & 74 & 47.67 \\
\hline III-IV & 98 & 52.33 \\
\hline Tumor size & & \\
\hline$\geq 5 \mathrm{~cm}$ & 82 & 36.05 \\
\hline Metastasis & 90 & 63.95 \\
\hline No & & \\
\hline Yes & 62 & \\
\hline
\end{tabular}

By the end of the follow-up, 116 (67.44\%) patients showed CR and PR to chemotherapy, while $56(32.56 \%)$ patients showed SD and PD. The correlation between the XRCC1 194 (Arg>Trp), 280 (Arg>His), and 399 ( $\mathrm{Arg}>\mathrm{GIn})$ polymorphisms and the response to chemotherapy is shown in Table 2. By logistic regression analysis, we found that the Trp/Trp genotype at XRCC1 194 (Arg>Trp) was associated with a CR+PR to chemotherapy when compared with the Arg/Arg genotype, and the adjusted OR $(95 \% \mathrm{Cl})$ was $0.17(0.05-0.58)$. However, we did not find a significant association between the 280 ( $\mathrm{Arg}>\mathrm{His})$ and 399 (Arg>Gln) gene polymorphisms and response to chemotherapy. We found that the Trp/Trp genotype were also associated with a higher risk of death when compared with the Arg/Arg genotype by multivariate Cox proportional hazard regression analysis, and the adjusted hazard ratio $(95 \% \mathrm{Cl})$ was $4.08(1.20-14.19)$ (Table 3). However, the XRCC1 280 (Arg>His) and 399 (Arg>Gln) polymorphisms were not correlated with OS of gastric cancer.

Table 2. Association between XRCC1 194 (Arg>Trp), 280 (Arg>His), and 399 (Arg>Gln) gene polymorphisms and response to chemotherapy.

\begin{tabular}{|c|c|c|c|c|c|c|c|c|}
\hline Gene & Total & $\%$ & $\mathrm{CR}+\mathrm{PR}$ & $\%$ & SD+PD & $\%$ & OR $(95 \% \mathrm{Cl})^{1}$ & $P$ value \\
\hline \multicolumn{9}{|c|}{ XRCC1 194 (Arg>Trp) } \\
\hline Arg/Arg & 81 & 47.09 & 62 & 53.45 & 19 & 33.93 & 1.0 (Ref.) & - \\
\hline Arg/Trp & 74 & 43.02 & 48 & 41.38 & 26 & 46.43 & $0.57(0.26-1.21)$ & 0.11 \\
\hline Trp/Trp & 17 & 9.88 & 6 & 5.17 & 11 & 19.64 & $0.17(0.05-0.58)$ & 0.001 \\
\hline \multicolumn{9}{|c|}{ XRCC1 280 (Arg>His) } \\
\hline Arg/Arg & 88 & 51.16 & 62 & 53.45 & 26 & 46.43 & 1.0 (Ref.) & - \\
\hline Arg/His & 66 & 38.37 & 43 & 37.07 & 23 & 41.07 & $0.78(0.38-1.65)$ & 0.48 \\
\hline $\mathrm{His} / \mathrm{His}$ & 18 & 10.47 & 11 & 9.48 & 7 & 12.50 & $0.66(0.21-2.25)$ & 0.44 \\
\hline \multicolumn{9}{|c|}{ XRCC1 399 (Arg >GIn) } \\
\hline Arg/Arg & 125 & 72.67 & 87 & 75.00 & 38 & 67.86 & 1.0 (Ref.) & - \\
\hline Arg/GIn & 31 & 18.02 & 20 & 17.24 & 11 & 19.64 & $0.79(0.32-2.03)$ & 0.59 \\
\hline $\mathrm{G} \ln / \mathrm{G} \ln$ & 16 & 9.30 & 9 & 7.76 & 7 & 12.50 & $0.56(0.17-1.92)$ & 0.28 \\
\hline
\end{tabular}

${ }^{1}$ Adjusted for gender, age, Lauren's type, TNM stage, and metastasis.

\section{DISCUSSION}

It is well known that genetic factors may contribute to the individualized response of patients to chemotherapy. XRCC1 serves as a scaffold factor in BER, for which functional polymorphisms 
Table 3. Association between XRCC1 194 ( $\operatorname{Arg}>\operatorname{Trp}$ ), 280 (Arg>His), and 399 (Arg>GIn) gene polymorphisms and overall survival of gastric cancer patients.

\begin{tabular}{l|c|c|c|c|c|c|c|c}
\hline Gene & Total & $\%$ & Event & $\%$ & Alive & $\%$ & HR (95\%Cl) & P value \\
\hline XRCC1 194 (Arg>Trp) & & & & & & & & \\
\hline Arg/Arg & 81 & 47.09 & 26 & 46.43 & 55 & 47.41 & 1.0 (Ref.) & - \\
\hline Arg/Trp & 74 & 43.02 & 23 & 41.07 & 51 & 43.97 & $1.46(0.69-3.09)$ & 0.28 \\
\hline Trp/Trp & 17 & 9.88 & 7 & 12.50 & 10 & 8.62 & $4.08(1.20-14.19)$ & 0.008 \\
\hline XRCC1 280 (Arg>His) & & & & & & & & \\
\hline Arg/Arg & 88 & 51.16 & 29 & 51.79 & 59 & 50.86 & $1.0(\operatorname{Ref})$. & - \\
\hline Arg/His & 66 & 38.37 & 21 & 37.50 & 45 & 38.79 & $1.19(0.56-2.50)$ & 0.62 \\
\hline His/His & 18 & 10.47 & 6 & 10.71 & 12 & 10.34 & $1.91(0.58-6.04)$ & 0.22 \\
\hline XRCC1 399 (Arg>GIn) & & & & & & & & 1.0 \\
\hline Arg/Arg (Ref.) & - \\
\hline Arg/Gln & 125 & 72.67 & 40 & 71.43 & 85 & 73.28 & $1.01(0.39-2.50)$ & 0.98 \\
\hline GIn/Gln & 31 & 18.02 & 10 & 17.86 & 21 & 18.10 & 1.01 \\
\hline
\end{tabular}

${ }^{1}$ Adjusted for gender, age, Lauren's type, TNM stage, and metastasis.

have been identified. The XRCC1 194 (Arg>Trp) allele variant is a hot spot in the research of XRCC1 polymorphisms, as it is linked with changes in DNA repair activity (Au et al., 2003). The induction of DNA damage is very relevant in this context, as it affects the efficiency and toxicity of platinum-based chemotherapy. In the present study, we found that XRCC1 194 (Arg>Trp) gene polymorphisms may contribute to the response to chemotherapy and OS of gastric cancer patients.

The XRCC1 gene is located on chromosome 19q13.2 and encodes a 633-amino acid scaffold protein. XRCC1 functions in a complex with many other components to facilitate BER and SSBR processes. Previous studies have reported the association between XRCC1 194 (Arg>Trp) and platinum-based chemotherapy in several kinds of cancers, such as non-small cell lung cancer, ovarian cancer, and cervical cancer (Cheng et al., 2009; Cui et al., 2012; Li and Li, 2013; Gu et al., 2015). In a group of Chinese patients, Cui et al. (2012) found that the $194 \mathrm{C} / \mathrm{C}$ and $399 \mathrm{G} / \mathrm{A}+\mathrm{A} / \mathrm{A}$ or $194 \mathrm{C} / \mathrm{C}$ genotypes were associated with an objectively worsened response to chemotherapy. In contrast, Cheng et al. (2009) reported that XRCC1 194 (Arg>Trp) did not influence the response of cervical cancer patients to platinum-based chemotherapy. Li and Li (2013) have reported a significant association between the XRCC1 194 (Arg>Trp) polymorphism and the treatment outcome of ovarian cancer. Gu et al. (2015) reported that genetic polymorphisms in the XRCC1 gene are correlated with a higher sensitivity to platinum-based chemotherapy in patients with nonsmall cell lung cancer.

With respect to the association between gastric cancer and XRCC1 194 (Arg>Trp), only three studies reported their association (Shim et al., 2010; Tahara et al., 2011; Zhang et al., 2013). Zhang et al. (2013) reported that the XRCC1 194 (Arg>Trp) variant may act as a favorable prognostic indicator of resected gastric cancer, especially in the diffuse-type. Tahara et al. (2011) showed an association between XRCC1 codon 194 Trp and more aggressive biological gastric cancer. Shim et al. (2010) studied a Korean population of gastric cancer patients and found that the XRCC1 194 CT genotype was associated with poor OS, compared with the CC homozygotes.

While our study corroborates these previous findings, it has two important limitations. First, there may be a selection bias, leading to an overestimation of the true size of the effects or to spurious findings. Second, the sample size of patients with gastric cancer is relatively small, which may limit the statistical power to find difference between the groups. Therefore, further large sample-size studies are urgently needed to confirm these results.

In conclusion, we found that the XRCC1 194 (Arg>Trp) polymorphism was correlated with a better response to chemotherapy and lower risk of death in patients with gastric cancer. Studies 
with a larger sample size are required to confirm the role of XRCC1 polymorphisms in the clinical outcome of gastric cancer.

\section{Conflicts of interest}

The authors declare no conflict of interest.

\section{REFERENCES}

Au WW, Salama SA and Sierra-Torres CH (2003). Functional characterization of polymorphisms in DNA repair genes using cytogenetic challenge assays. Environ. Health Perspect. 111: 1843-1850.http://dx.doi.org/10.1289/ehp.6632

Cheng XD, Lu WG, Ye F, Wan XY, et al. (2009). The association of XRCC1 gene single nucleotide polymorphisms with response to neoadjuvant chemotherapy in locally advanced cervical carcinoma. J. Exp. Clin. Cancer Res. 28: 91.http:// dx.doi.org/10.1186/1756-9966-28-91

Cui Z, Yin Z, Li X, Wu W, et al. (2012). Association between polymorphisms in XRCC1 gene and clinical outcomes of patients with lung cancer: a meta-analysis. BMC Cancer 12: 71.http://dx.doi.org/10.1186/1471-2407-12-71

Duarte MC, Colombo J, Rossit AR, Caetano A, et al. (2005). Polymorphisms of DNA repair genes XRCC1 and XRCC3, interaction with environmental exposure and risk of chronic gastritis and gastric cancer. World J. Gastroenterol. 11: 65936600.http://dx.doi.org/10.3748/wig.v11.i42.6593

Duell EJ, Millikan RC, Pittman GS, Winkel S, et al. (2001). Polymorphisms in the DNA repair gene XRCC1 and breast cancer. Cancer Epidemiol. Biomarkers Prev. 10: 217-222.

Gu AQ, Wang WM, Chen WY, Shi CL, et al. (2015). XRCC1 genetic polymorphisms and sensitivity to platinum-based drugs in non-small cell lung cancer: an update meta-analysis based on 4708 subjects. Int. J. Clin. Exp. Med. 8: 145-154.

International Agency for Research on Cancer Stomach Cancer (2012). Estimated Incidence, Mortality and Prevalence worldwide in 2012. http://globocan.iarc.fr/Pages/fact_sheets_cancer.aspx. Accessed August 1, 2015.

Li K and Li W (2013). Association between polymorphisms of XRCC1 and ADPRT genes and ovarian cancer survival with platinum-based chemotherapy in Chinese population. Mol. Cell. Biochem. 372: 27-33.http://dx.doi.org/10.1007/s11010$\underline{012-1442-4}$

Lindahl T and Wood RD (1999). Quality control by DNA repair. Science 286: 1897-1905.http://dx.doi.org/10.1126/ science.286.5446.1897

Shim HJ, Yun JY, Hwang JE, Bae WK, et al. (2010). BRCA1 and XRCC1 polymorphisms associated with survival in advanced gastric cancer treated with taxane and cisplatin. Cancer Sci. 101: 1247-1254.http://dx.doi.org/10.1111/j.13497006.2010.01514.x

Tahara T, Shibata T, Nakamura M, Yamashita H, et al. (2011). Effect of genetic polymorphisms related to DNA repair and the xenobiotic pathway on the prognosis and survival of gastric cancer patients. Anticancer Res. 31: 705-710.

Therasse P, Arbuck SG, Eisenhauer EA, Wanders J, et al. (2000). New guidelines to evaluate the response to treatment in solid tumors. European Organization for Research and Treatment of Cancer, National Cancer Institute of the United States, National Cancer Institute of Canada. J. Natl. Cancer Inst. 92: 205-216.http://dx.doi.org/10.1093/jnci/92.3.205

Thompson LH and West MG (2000). XRCC1 keeps DNA from getting stranded. Mutat. Res. 459: 1-18.http://dx.doi.org/10.1016/ S0921-8777(99)00058-0

Xu J, Ma J, Zong HT, Wang SY, et al. (2014). Pharmacogenetic role of XRCC1 polymorphisms on the clinical outcome of gastric cancer patients with platinum-based chemotherapy: a systematic review and meta-analysis. Genet. Mol. Res. 13: 1438-1446.http://dx.doi.org/10.4238/2014.March.6.2

Zhang Y, Wang M, Gu D, Wu D, et al. (2013). Association of XRCC1 gene polymorphisms with the survival and clinicopathological characteristics of gastric cancer. DNA Cell Biol. 32: 111-118.http://dx.doi.org/10.1089/dna.2012.1840 